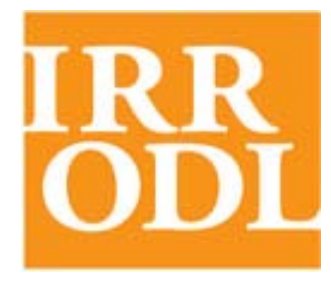

International

Review of

Research in Open

and Distance

Learning

Vol. 12.1

January -2011

\section{Preconditions for Post-Employment Learning: Preliminary Results from Ongoing Research}

\author{
Linda Salter \\ Capella University, USA
}

\begin{abstract}
This article describes the first phase of a two-phase, mixed-method study. The study, now in progress, explores how and to what extent willingness to engage in learning in mature adulthood is influenced by prior experiences and specific individual personality variables, such as perceived locus of control and degree of self-efficacy. Study participants in this phase are 20 active adults over the age of 50 who participate in various formal and informal programs at a YMCA in a suburb of Seattle, Washington. Preliminary results thus far are discussed with respect to how they may inform educators of mature adults in open education settings. A profile of the characteristics of mature adults likely to be engaged in learning activities is beginning to emerge. A larger sample of participants taken from the same population is now being studied to confirm or refute the value of this profile.
\end{abstract}

Keywords: Locus of control; mature learners; preconditions; prior experience; self-efficacy 


\section{Introduction}

The accumulated body of knowledge and prior experiences encapsulated in the concept educators refer to as prior learning is a characteristic of adult learning that sets it apart from learning earlier in life. In higher education contexts, prior learning is becoming the focus of adult learner assessments in order to evaluate how much relevant information and skill the mature learner brings with him or her to a formal learning environment. Writing in The Chronicle of Higher Education, Eric Hoover notes that the benefits of taking prior learning into account include an increase in graduation rates and a decrease in the amount of time taken to complete degree programs when such assessments are used (2010).

As well as being used by educators to evaluate incoming students and to assign credit in some cases, prior learning has also been studied as a topic for reflection in an effort to facilitate transformative learning. In a study of a sample of current and former students at an open university, Stevens, Gerber, and Hendra (2010) report that the process of preparing a portfolio of prior learning experiences appears to enhance learning transfer between the classroom and the real world as well as to alter learners' perspectives about themselves. The latter finding satisfied Stevens et al. that transformative learning was fostered by the prior learning portfolio writing process and had enabled the participants in their study to become "more inclusive, discriminating, open, emotionally capable of change, and reflective" (Mezirow as cited in Stevens, Gerber, \& Hendra, 2010, p. 382).

Along with being influenced by more prior learning experiences, mature adult learning is also distinct from earlier learning with respect to the role of self-regulation. In a study of the implications of increasing longevity for society and for individuals, Freund, Nikitin, and Ritter (2009) found that as adults age, they are progressively less constrained by social norms and more dependent on self-regulating mechanisms in many domains of their lives, including education. With respect to activities later in life, Freund et al. suggest that prior development and subsequent maintenance of self-regulatory competencies, such as setting and pursuing personal goals, are preconditions for what they describe as successful or positive aging.

This article describes ongoing doctoral research being conducted by the author. The study explores how and to what extent willingness to engage in learning in mature adulthood is influenced by prior learning experiences and specific individual personality variables related to self-regulation, such as perceived locus of control and degree of self-efficacy.

\section{Self-Directed Learning}

Adults' desire to take responsibility for their own learning and their capacity to do so are key assumptions of the andragogical model of learning, a model that describes processes unique to learning in adulthood. With respect to how this assumption is related to the practice of adult education, proponents of andragogy have emphasized that "it is the sense of personal autonomy, not self-teaching, that seems to be most important for adults” (Knowles, Holton, \& Swanson, 2005, p. 189) and that "the biggest problems arise when adult learners want to have more 
independence in their learning but are denied that opportunity” (p. 189). Providing such opportunities is central to the practice of learner-centred education of the type often delivered in non-traditional formats such as open and distance learning environments (see www.col.org).

\section{Self-Directed Versus Self-Regulated Learning}

According to Loyens and Magda (2008), self-directed learning "as a design feature of the learning environment stresses students' freedom in pursuit of their learning” (p. 418); whereas, self-regulated learning refers to a process in which learners choose to engage in learning and to employ strategies on tasks that may have been selected independently or assigned by a teacher. The importance of this distinction lies in the implication that self-directed learning is the broader concept, is a characteristic of both the learner and the environment, and assumes the learner has complete control over the experience. Self-regulation, on the other hand, is a learner characteristic, enabling learners to engage in learning with or without the initial input of an instructor.

\section{Open Learning}

The term open learning first came into common use early in the second half of the $20^{\text {th }}$ century during a time of increasing international focus on issues of social justice. As an element of social justice, proponents of open learning took the position that education should be available and accessible for everyone, without barriers based on ethnicity, race, gender, age, and socioeconomic status. Although in recent years the term has been somewhat conflated with others such as e-learning and mobile-learning, a distinction can be made between open learning and these other concepts. Open learning can be defined as "both a process which focuses on access to educational opportunities and a philosophy which makes learning more client and student centred" (Paine as cited in Gaskell, p. 1, 2007). E-learning and mobile learning are narrower concepts, more specifically associated with particular methods of delivering education. However, these technological advances do not necessarily guarantee openness in learning because access to education delivered in these manners is dependent upon the availability of specific equipment and the ability to use it (Gaskell, 2007). In the current study, all participants had access to the same learning opportunities and, as mature adults, could all be described as members of a demographic group - adult non-traditional learners - explicitly served by open learning institutions.

\section{Non-Traditional Learners}

Mature individuals enrolled in education programs are considered to be non-traditional learners. The U.S. Department of Education (2005) defines non-traditional students as "students who possess one or more of several characteristics, including delayed enrollment, part-time student status, full-time employment, financial independence, responsibility for dependents, and enrollment after the twenty-fifth birthday." Mature adult learners typically possess one or more of the traits associated with non-traditional learners. 
Learning environments provided by open and distance learning institutions are designed to meet the needs of such non-traditional learners. The Commonwealth of Learning (COL) Web site describes open and distant learning as being characterized by

. . . the convergence of open and distance learning methods, media and classroom strategies; learner-centred philosophy; recognition of diversity in learning styles and in learners' needs; recognition of the importance of equity in curriculum and pedagogy; use of a variety of learning resources and media; fostering of lifelong learning habits and skills in learners and staff (COL, 2000).

\section{Mature Learners}

According to the U.S. Census Bureau (2005), 12\% of the U.S. population was 65 or older in 2003, and it is expected that by 2030, that percentage will have risen to $20 \%$. Earlier studies predicted that this segment of the population would become increasingly diverse with respect to ethnic backgrounds, native languages, and formal education levels attained, and would include proportionately more women than men as compared to demographics around the turn of the $21^{\text {st }}$ century (Manheimer, 2002; Sticht, 1998). A 2006 report prepared for Congress by a specialist in demographic research describes trends consistent with such predictions (Shrestha, 2006). Between 1950 and 2005, the population of the United States became older, more likely to be female, and more ethnically and culturally diverse.

Because older learners seem to engage in what is essentially a cost-benefit analysis when contemplating learning new skills and are influenced by their own personalities as well as by previous learning experiences in conducting that analysis, both internal factors (such as motivation) and external variables (such as learning environments) must be better understood if learning is to be facilitated throughout the lifespan (Wlodkowski, 1999).

\section{The Dual Role of Experience in Adult Learning}

Experience is explicitly used to facilitate adult learning through the use of strategies and activities such as field-based learning, active learning classroom work, and community-based social action (Fenwick, 2003). Additionally, for adults, there is evidence that previous learning experiences impact motivation to learn and expectations regarding outcomes (Belzer, 2004).

\section{Learning through experience.}

Experiential learning in adulthood "involves adults connecting what they have learned from current experiences to those in the past as well as to possible future situations" (Merriam \& Caffarella, 1999, p. 246). The process during which adults engage in experiential learning is described as meaning-making and problem-solving by adherents of constructivist and 
transformative learning theories, two influential theories in the evolution of adult education (Fenwick, 2003).

\section{Influence of prior experience.}

In a study of the impact of prior learning experiences on middle-aged adults currently enrolled in a General Educational Development (GED) program, Belzer (2004) found that "experiences of learning contexts themselves may play a significant and sometimes confounding role in adult learning and are worthy of further examination” (p. 56). Specifically, the findings of the study indicate that learners' expectations of current learning activities arise directly out of earlier learning experiences. If those earlier experiences were either negative or sharply different from the current experience, there is likely to be a negative impact on attitudes and outcomes.

\section{Locus of Control}

Locus of control refers to one dimension that can be used to describe how individuals explain the events they experience. Using this dimension, these explanations are examined with respect to whether the individual attributes events and outcomes to forces within or beyond his or her own control (Ormond, 2004). Increasing age appears to be associated with an internal locus of control (Siri, Gemlk, \& Sur, 2007).

\section{Self-Efficacy}

Self-efficacy is a set of beliefs held by an individual concerning his or her ability to perform. This set of beliefs is thought to impact learning with respect to willingness to engage in learning, having or lacking motivation and perseverance, and the realization of successful outcomes. Belief about the self tends to be "specific to particular domains, tasks, or situations" (Ormond, 2004, p. 142). According to a study of mature adults in rehabilitation after serious illness or injury, positive self-efficacy beliefs about ability to recover seem to be associated with optimism and with favorable outcomes (Resnick, 2002).

\section{Formality}

Learning in the context of older adulthood has been studied primarily "in terms of formal, institutionally sponsored programs” (Chen, Kim, Moon, \& Merriam, 2008, p. 17). However, learning later in life tends to be an informal activity in the sense that it is usually optional and not likely to be related to employment. It is often characterized as being a leisure time or recreational activity and typically occurs in "nonformal learning projects existing outside of educational institutions" (Chen et al., 2008, p. 17). After reviewing the relevant literature published between 1980 and 2006, Chen et al. (2008) concluded that more research by and for adult educators is needed in order to better understand the characteristics and interests of older learners and to examine "the potential for lifelong growth and development in nonformal and informal learning" (p. 17). 


\section{Learning Styles}

Using Kolb’s Learning Style Inventory (1976), Truluck and Courtenay (1999) conducted a study of 172 adults ranging in age from 55 to over 75. They found no significant relationship between age or gender or educational level and learning style preference in the study group as a whole. With respect to age, when the researchers examined the data of sub-groups in increments of 10 years of chronological age, they did find some indication that learning preferences change over time during mature adulthood. Younger mature adults indicated an inclination to use hands-on learning, the next older group tended to prefer a combination of visual and auditory modes, and the oldest group also preferred visual and auditory modes but also believed they learned by thinking. Such results suggest that in order to better understand learning in older individuals, it is necessary to move beyond demographic variables such as age, gender, and level of educational attainment.

\section{Mature Learners as Members of the Pre-Digital Generation}

The recent increase in the use of digital technologies in daily life and in education has highlighted a generational difference between older and younger adults with respect to learning styles and the new media that dominate learning environments. Evidence is beginning to be found suggesting that adults under the age of 30 who have been exposed to digital technologies for their entire lives are developing learning styles and strategies distinct from their 'pre-digital' elders. Digital generation learners seem to be more skilled at processing more than one task at a time, less dependent upon linear thinking and more open to random input of information, more comfortable with graphics, more likely to be active as opposed to passive learners, less likely to make a distinction between work and play, and more likely to expect a reward of some kind for their efforts (Salopek, 2003).

The influence of digital technology on learning has also been studied with respect to new concepts of literacy. Learners for whom pre-digital media were and are dominant may have not yet developed digital literacies sufficient to be considered competent in technologically based learning environments. Mature, pre-digital learners may find themselves at a disadvantage compared to their younger counterparts with respect to their ability to "cope with a complex mix of visual, oral, and interactive media as well as traditional text” (Cilia, Aiello, \& Bartolomé, 2006, p. 440).

\section{Method}

\section{Participants}

The 20 participants in this study are enrolled in various YMCA senior citizen programs and classes, are over the age of 50, describe themselves as physically and mentally active, and agreed to voluntarily participate after a brief interview with the researcher. 
Regarding employment status, nine participants described themselves as retired or semi-retired, and six reported being retired and doing volunteer work. The remaining five participants indicated they were semi-retired and employed. In addition, two of the retired participants described themselves as caregivers. As shown in Table 1, the participants include men and women ranging in age from 50 to more than 80 years old. Highest level of educational achievement was also recorded.

Table 1

Age and Gender of Participants

\begin{tabular}{lc} 
Category & Number of participants \\
\hline Men & 9 \\
Women & 11 \\
$50-60$ & 2 \\
$60-70$ & 4 \\
$70-80$ & 12 \\
$80+$ & 2 \\
Some college or vocational training & 6 \\
College degree or vocational certificate & 5 \\
Graduate degree or professional training & 9
\end{tabular}

\section{Procedures}

\section{Sampling.}

A sample of opportunity was used in this study. Twenty participants were recruited by the researcher from the membership of a YMCA branch in a suburb of Seattle, WA. According to the U.S. Census Bureau (2006), the county in which the participants reside is characterized by a population that is above the national averages for income and education and that is less ethnically diverse. Sample size was arbitrarily chosen by the researcher, taking into consideration time and space constraints. The YMCA facility was selected because of the extensive services offered to mature members. Access was granted to the researcher by the executive director of the facility.

\section{Data collection.}

The researcher met with each participant individually or in small groups in an on-site room provided by the YMCA. The meetings occurred over a span of one business week and lasted 20 to 30 minutes each. During the meetings, the participants read and signed the informed consent form, answered one oral question, and completed the three data collection instruments.

The three data collection instruments included two commonly used scales and a questionnaire written by the researcher. To measure self-efficacy, Schwarzer and Jerusalem's General 
Perceived Self-Efficacy Scale (2000) was used. Rotter's Locus of Control Scale (1966) was employed to determine the participants' tendencies to attribute control to either internal or external forces. The questionnaire, which was pilot tested for clarity prior to use in this study, consisted of 12 items soliciting information regarding the participants' prior and current learning experiences, as well as limited demographic data. At the conclusion of the meeting, the participants were asked for a brief description of the characteristics they associated with adults in their own age group who continued to engage in learning activities. The researcher recorded the responses to the interview question in written form.

\section{Results}

\section{Oral Question}

Each participant was asked to briefly describe the characteristics they observed in actively learning adults in their own age groups. The researcher assigned each descriptor to one of five domains (affective, cognitive, health, psychomotor, or social) and then totaled the number of descriptors in each domain or combination of domains. The most commonly used descriptors were those assigned to the cognitive and affective domains.

\section{Self-Efficacy}

Out of a possible score of 40, with high scores indicating strong self-efficacy beliefs, all of the participants indicated at least moderate, and in many cases, elevated self-efficacy beliefs. Scores ranged from 30 to 38, with the most common score being 35 .

\section{Locus of Control}

The lower the score on this scale the more the respondent is categorized as tending to attribute outcomes to internal versus external forces. Possible scores range from 0 (maximum internal locus) to 23 (maximum external locus). The scores obtained ranged from 2 to 12, with most participants scoring between 5 and 10 .

\section{Questionnaire Responses}

Nine of the questionnaire items were non-demographic in nature. Those of most interest in this study at this stage are briefly discussed below.

Question 3 asked participants to select all that applied from a list of 18 activities that they might engage in on a typical day, and responses were subsequently categorized as belonging to creative, cognitive, physical, social, or learning domains.

Activities categorized as belonging to the learning domain--the domain of interest in this study-are those that explicitly involve learning, teaching, or practising new skills or knowledge. 
Informed by the writing of Plumb (2008), for the purpose of this study, learning is defined not as a result of another activity but as an activity in itself that is engaged in, to varying degrees, by all developing humans throughout the life course. Responses to question 3 by assigned domain are depicted in Table 2.

Table 2

Daily Activities Distribution by Domain

$\begin{array}{lc}\text { Domain } & \text { Total number of responses (all participants) } \\ \text { Creative } & 27 \\ \text { Cognitive } & 40 \\ \text { Learning } & 37 \\ \text { Physical } & 40 \\ \text { Social } & 37\end{array}$

Other questions that elicited potentially useful results asked participants to indicate what they believed to be their most productive learning age, environment, and sources.

The most commonly selected learning environments were in a school or other formal classroom (32 selections) and at work or in the military (31 selections). At home and at a church or another community organization were the other two choices and were chosen 24 times each.

Participants were given six choices from which to select what they perceived to be the age(s) most conducive to their learning: as a child, as a teenager, as an adult under 50, as an adult over 50, in the past 5 years, and in the past year. As an adult under 50 was chosen 12 times, as an adult over 50 was chosen 7 times, and in the past 5 years was chosen once.

Information regarding productive sources for learning was gathered by asking participants to select from informal choices, such as family members, friends, spiritual advisors, and public figures, and the more formal choices of schoolteachers or other instructors and work or military or other organization supervisors. Participants selected schoolteachers or other instructors 16 times. The number of times the other options chosen were as follows: older family members (12), younger family members (11), peers (11), workplace or military or other organization supervisors (10), spiritual advisors (4), and public figures (2).

One item asked participants to select one or more from a list of four categories of memories as their strongest type of recollections about their learning experiences. Responses to this question are depicted in Table 3. 
Table 3

Distribution of Learning Experience Memories

\begin{tabular}{lc} 
Memory & Total number of res \\
\hline Tests, grades, passing, failing & 6 \\
Friends & 11 \\
Teachers, supervisors & 11 \\
Subjects, skills & 17
\end{tabular}

In another item, participants were asked to indicate whether they found self-study or study facilitated by an instructor to be most productive for them. One respondent chose neither, one chose independent study only, six chose facilitation by an instructor only, and twelve participants selected both.

Participants were also provided with several options from which to select to describe what learning methods they believed to be most useful for them. Their responses are depicted in Table 4.

Table 4

Learning Style Preferences

\begin{tabular}{lc} 
Style & Number of times selected \\
\hline Watching others & 9 \\
Listening to others & 10 \\
Reading instructions & 7 \\
Trial and error & 11 \\
Two or more of the above & 18
\end{tabular}

\section{Emergent Themes}

Scores from the two scales, responses from the questionnaire, and answers to the oral question were examined using $\mathrm{NVivo}^{\mathrm{TM}}$ qualitative analysis software. The purpose of the analysis was to search for themes or tendencies with respect to prior learning experiences, levels of self-efficacy, and type of locus of control that appear to be typical of this sample of actively engaged mature learners.

Question 3 on the questionnaire elicited responses regarding typical daily activities. Responses were coded by domain. The domains coded were physical, social, cognitive, creative, and explicit learning. Respondents who indicated typical daily activities in the learning domain were designated as cases of currently engaged learners. This trait was subsequently examined to determine whether a relationship appears to exist between currently engaged learning behavior and other variables. Following completion of coding, associations between learning behavior and 
several variables were identified. Current engagement in learning was found to be associated with numerous preconditions: internal locus of control, strong self-efficacy scores, a focus on learning process versus learning outcome, designation of formal learning environments and sources as more influential than informal environments and sources, a perception that mid-adulthood represented the most productive learning period, and current engagement in social relationships and activities. An association was identified when more than half of the cases are characterized both by evidence of current learning engagement and of the other variable in question. Table 5 depicts the thematic evidence used to justify the identification of several preconditions for engagement in learning in mature adulthood.

Table 5

Relationships between Current Engagement in Learning Activities and Preconditions

\begin{tabular}{ll} 
Precondition & Current engagement \\
\hline Focus on learning process & Associated $(12 / 20$ cases $)$ \\
Focus on learning outcome & Not associated $(2 / 20$ cases $)$ \\
Preference: formal learning environments & Associated $(13 / 20$ cases $)$ \\
Preference: formal learning sources & Associated $(12 / 20$ cases $)$ \\
Strong self-efficacy & Associated $(12 / 20$ cases $)$ \\
Internal locus of control & Associated (15/20 cases) \\
Current social engagement & Associated (14/20 cases) \\
Continuous learning through adulthood & Associated ( $16 / 20$ cases $)$
\end{tabular}

\section{Limitations}

The qualitative nature of the data collected, the small size of the sample, and the non-random sampling used limits the inferential value of the study at the phase one stage. However, in the second phase, data collected from a larger sample is being compared quantitatively to the findings from phase one using a student t-test. If the t-test results indicate that the samples are similar with respect to variables relevant to the research, some amount of population validity may be indicated (Gall, Gall, \& Borg, 2003).

\section{Discussion}

The purpose of this first phase of this study is to generate a list of possible preconditions for willingness to engage in learning activities in post-employment adulthood. Data from a second, larger sample of participants from the same population will be analyzed and compared to the first set of data using a student t-test to determine if the same preconditions appear to be present. At this point, a profile describing the history, personal attributes, and current lifestyle of welleducated, mature adults currently engaged in learning activities is beginning to emerge: 
- an educational history associated with success, personal relationships with peers and instructors, and a focus on the subjects studied or skills acquired as opposed to a focus on tests and measured outcomes;

- learning activities extended beyond traditional school years and continuing through adulthood;

- personal attributes including positive self-efficacy and internal locus of control;

- a current lifestyle that includes physical activity and regular social engagement.

If this profile proves to be a valid and reliable indicator of the conditions that pre-dispose mature adults to continue learning, there are numerous implications for researchers and practitioners in the field of adult education.

\section{Implications for Today}

Mature learners at this time in history are members of the so-called pre-digital generation and have been referred to as digital immigrants (Prensky, 2001). They did not grow up with the digital technology that the generation born after 1980 has been exposed to throughout their learning lives, and do not appear to make a strong connection between the use of such technology and education. They are also more likely than younger learners to have traditional, teachercentred education backgrounds and traditional expectations for learning environments and sources.

Prensky's generational predictions appear to be borne out in observations made incidentally in a recent study of the effectiveness of a constructivist online learning environment for adults (ages 20 - 49). The researcher noted some differences between the younger and older adults in the study. For example, it was observed that the older adults spent more time on their course work, and were more interested in collaborative learning, more inclined to seek out direct contact with their peers, less motivated by course achievement, and less concerned with real-world applications than their younger colleagues (Ruey, 2010).

As noted earlier in the Results section, a majority of the participants in this study believe formal, traditional learning contexts have been the most productive for them. Anecdotally, conversations with participants revealed that they continue to believe they learn best when they attend a traditional class led by an instructor who is a subject matter expert. When recollecting their prior learning experiences, they tended to refer more often to the subject matter studied and the process of learning itself, along with relationships formed with peers and instructors, than to outcomes in the form of grades achieved.

A previous study found that learning is inhibited when current experiences differ from prior or expected experiences (Belzer, 2004). If the findings of phase one of this study are confirmed in the second, larger sample without a significant difference between the samples, it could be interpreted as indicative of the need to provide older learners in open and distance learning contexts with hybrid learning environments, including regular and interactive engagement with a facilitator and with their peers. Another set of findings that may argue for flexibility and variety 
with respect to the delivery of education to older learners is reflected in their self-reported learning style preferences. Nearly all the participants selected at least two, and in many cases, more than two learning styles.

It appears that non-traditional learning designers and facilitators can best meet the needs of the current generation of mature learners by attending to the comfort level they have with the learning context. That comfort level is impacted by how similar the context is to their prior contexts and can be improved not only by modifying the context where possible and necessary, but also by providing mature learners with explicit details about what to expect when they enter a program. Future generations of mature learners will probably have more experience with what are now considered non-traditional learning contexts, including the use of technology in distance programs. However, as older learners, they will have other prior experiences and tendencies that will continue to impact learning in spite of this expected increase in familiarity with nontraditional learning environments.

\section{Implications for the Future}

The profile that is being suggested here is one in which today's engaged mature learners are likely to have a history of positive experiences with learning, learning that was perceived to have continued through adulthood, positive self-efficacy, and an internal locus of control. Regarding other aspects of their lives, the participants in this study also shared active social lives and regular physical exercise. In order to prepare for the mature learners of the future, the fields of adult education in general and open learning in particular might benefit from more attention being paid by researchers and practitioners to these experiences, attributes, and lifestyle characteristics now.

In broad, societal terms, a case can be made for adult educators and other members of the helping professions to advocate with public agencies and in the business sector on behalf of their learners with respect to improving access to continuing education throughout their adult lives and on and off job sites. The participants in this study perceived their adult years and activities to have been characterized by continued learning. Within learning institutions, this advocacy could also be extended to working with administrations to encourage the expansion of opportunities for social interaction and participation in physical fitness programs for adults of all ages. Since it may be the case that physically fit, socially active mature adults are predisposed to engage in learning activities, it follows logically that it could be helpful to attend to these aspects of adult lifestyles before these adults reach older adulthood.

There are, of course, also implications of direct interest to practitioners of adult education. These implications apply especially to the use of social and collaborative learning and transformative and critical learning practices in physical and virtual classrooms.

Participants in this study indicated via their recollections that their prior educational experiences had included social connections and a sense of belonging. Evidence abounds for the essential nature of social and collaborative learning for adults and particularly for adults in distance education programs (Bruffee, 1999; Clark \& Mayer, 2003). Some advocates of collaborative 
learning assume that "all knowledge is socially constructed . . . in an ongoing negotiation to consensus that involves increasingly larger and more complex communities of knowledgeable peers” (Bruffee, 1999, p. 52). In the context of higher or continuing education, an instructor committed to promoting this kind of learning needs to be skilled both in using and fostering collaboration. According to Bruffee (1999), fostering such learning depends on the ability of the facilitator to assist learners in creating a so-called knowledge community and in developing the linguistic and communicative skills necessary to be an engaged, contributing member of that community.

These collaborative communities can be formed and have been found to thrive in online learning contexts. Collaborative tools found to be effective include providing concurrency such that a group of learners is proceeding through a program at the same time, and including curricular activities that require learners to work in groups via whatever technology is available and appropriate (Clark \& Mayer, 2003).

Providing younger adult learners now with collaborative and socially engaging learning environments may pay off for learners and educators alike in the future if the mature learners of the future come to the learning environment with a personal history of ongoing membership in a knowledge community. However, it seems that engagement in learning is also associated with positive self-efficacy beliefs and an internal locus of control. Fostering these individual attributes presents a different challenge for educators than facilitating social learning does.

In order to encourage positive self-efficacy and an internal locus of control in younger adult learners who do not demonstrate such traits now, educators could consider using techniques such as critical questioning. The goal of such techniques is to "actively encourage critical reflection through which individuals can investigate their meaning schemes and perspectives" (Cranton, 1994, p. 169). In other words, learners who currently have low expectations regarding their abilities and learning outcomes and/or who tend to attribute outcomes to external forces rather than to themselves could be helped by analyzing how and why they came to hold these beliefs and recognizing the impact of those beliefs on their learning. Transformative learning theory holds that learners who successfully engage in such critical reflections will ultimately be able to construct new, more effective and realistic sets of assumptions and expectations.

\section{Questions to be Answered}

As is often the case, preliminary results raise more questions than they answer. These questions are beyond the scope of this study but warrant further investigation.

1. Are social engagement and physical activity as preconditions characteristic of the learners' lives throughout adulthood or can they play a particular role in enhancing motivation to learn later in life?

2. How do self-efficacy and locus of control beliefs develop and how amenable are they to intervention and modification by means of educational practices? 
3. The majority of these successful mature learners had high levels of education and/or professional achievement. Are mature adults with lower levels of education and occupational status who nonetheless had positive prior experiences with learning equally predisposed to continue learning as they age?

4. Did prior learning success predispose these learners to focus on the subject matter and processes of learning rather than on outcomes?

5. Comparing formal to informal prior learning, do late-in-life learners rely on one more than the other when constructing new understandings? Are the skills and knowledge previously acquired stored and subsequently accessed based on whether the original experience was formal or informal?

6. What is the role of learning in promoting successful aging as perceived by the mature individuals themselves? Is it beneficial for all mature adults, assuming nominal physical and cognitive functioning, or is the desire to continue learning itself an individual attribute?

\section{Final Thoughts}

In this first phase of the study, an item on the questionnaire completed by the participants asked them to indicate how they felt contemplating learning something new (excited, calm, worried, or no change), and another asked them how they felt after they learned something new (proud, satisfied, relieved, or no change). Regarding their pre-learning experience attitude, the majority of participants selected the adjective excited to describe their feelings, and with respect to how they felt afterwards, most chose either proud or satisfied. One participant added a write-in option to the item asking him how he felt after acquiring a new skill or new knowledge. He said he felt surprised. To have learners who are excited at the prospect of learning and who feel pride and satisfaction as a result of their learning experience--and even some whose level of comfort with learning allows good-humored self-deprecation - should be the goal of educators of adults at all stages in their lives. But to find these attributes in a group of such mature learners is as heartening as it is intriguing. In a future that will doubtlessly be characterized by an aging population of learners, there is reason to believe that there is much we in the field of adult education can learn from the successful mature learners of today to prepare for those of tomorrow. 


\section{References}

Belzer, A. (2004). It's not like normal school: The role of prior learning contexts in adult learning. Adult Education Quarterly, 55(1), 41-59.

Bruffee, K. (1999). Collaborative learning: Higher education, interdependence, and the authority of knowledge. Baltimore, MD: The Johns Hopkins University Press.

Chen, L., Kim, Y., Moon, P., \& Merriam, S. (2008). A review and critique of the portrayal of older adult learners in adult education journals, 1980 - 2006. Adult Education Quarterly, 57(1), 3-21.

Cilia, W., Aiello, M., \& Bartolomé, A. (2006). Self-regulated learning and new literacies: An experience at the University of Barcelona. European Journal of Education, 41(3/4).

Clark, R., \& Mayer, R. (2003). E-learning and the science of instruction. San Francisco, CA: John Wiley \& Sons.

Commonwealth of Learning. (2000). An introduction to open and distant learning. Retrieved from http://www.col.org/ODLIntro/introODL.htm

Cranton, P. (1994). Understanding and promoting transformative learning. San Francisco, CA: Jossey-Bass Publishing.

Fenwick, T. (2003). Learning through experience: Troubling orthodoxies and intersecting questions. Malabar, FL: Krieger Publishing Company.

Freund, A., Nikitin, J., \& Ritter, J. (2009). Psychological consequences of longevity. Human Development, 52(1), 1-37.

Gall, M., Gall, J., \& Borg, W. (2003). Educational research: An introduction (7th ed.). Boston, MA: Allyn \& Bacon.

Gaskell, A. (2007). Editorial: Open learning and e-learning. Open Learning, 22(1), 1-4.

Hoover, E. (2010). Where life earns credit: Prior learning gets a fresh assessment. The Chronicle of Higher Education, 56(27).

Knowles, M., Holton, E., \& Swanson, R. (2005). The adult learner: The definitive classic in adult education and human resource development (6th ed.). Burlington, MA: Elsevier.

Loyens, S., \& Magda, J. (2008). Self-directed learning in problem-based learning and its relationships with self-regulated learning. Educational Psychology Review, 20, 411-427. 
Manheimer, R. (2002). Older adult education in the United States: Trends and predictions. Retrieved from http://www.unca.edu/ncccr/Reports/

Merriam, S., \& Caffarella, R. (1999). Learning in adulthood: A comprehensive guide (2nd ed.). San Francisco, CA: Jossey-Bass Inc.

Ormond, J. (2004). Human learning. Upper Saddle River, NJ: Pearson Prentice Hall.

Plumb, D. (2008). Learning as dwelling. Studies in the Education of Adults, 40(1), 62-79.

Prensky, M. (2001). Digital natives, digital immigrants. Retrieved from http://www.wisc.edu/depdhtm/TSarticals/Digital\%20Natives.htm

Resnick, B. (2002). The impact of self-efficacy and outcome expectations on functional status in older adults. Topics in Geriatric Rehabilitation, 17(4), 1-10.

Rotter's locus of control scale (1966). Retrieved from http://www.ballarat.edu.au/bssh/psych/Rotter

Ruey, S. (2010). A case study of constructivist instructional strategies for adult online learning. British Journal of Educational Technology, 41(5).

Salopek, J. (2003). Going native: Cross the generation gap by learning to speak game. Training \& Development, 57(6).

Schwarzer, R., \& Jerusalem, M. (2000). General perceived self-efficacy. Retrieved from http://web.fu-berlin.de/gesudn/skalen

Shrestha, L. (2006). CRS report for Congress: The changing demographic profile of the United States. Retrieved from www.fas.org/sgp/crs/misc/RL32701.pdf

Siri, U., Gemlk, H., \& Sur, H. (2007). A comparative analysis of internal-external locus of control among hospital personnel in Turkey and in managerial implication on health sector. Humanity and Social Sciences Journal, 2(1), 51-62.

Stevens, K., Gerber, D., \& Hendra, R. (2010). Transformational learning through prior learning assessment. Adult Education Quarterly, 60(4), 377-404.

Sticht, T. (n.d.) Beyond 2000: Future directions for adult education. Retrieved from http://www/nald.ca/Fulltext/beyond/cover.html

Truluck, J., \& Courtenay, B. (1999). Learning style preference among older adults. Educational Gerontology, 25(3), 221-236. 
U.S. Census Bureau. (2006). King County, Washington: 2006 American community survey data profile highlights. Retrieved from http://factfinder.census.gov

U.S. Department of Education, National Center for Educational Statistics. (2005). Digest of education statistics. Washington, DC: U.S. Department of Education. Retrieved from http://wfnetwork.bc.edu/glossary entry.php?term+Non-Traditional

Wlodkowski, R. (1999). Enhancing adult motivation to learn: A comprehensive guide for teaching all adults. San Francisco, CA: Jossey-Bass.

\section{Athabasca University $\mathbf{A}$}

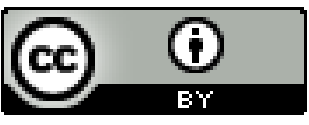

